\title{
Triple elevation of ALT is indicative of blunt hepatic trauma. Our local experience at rural district hospital
}

\author{
Asri Che Jusoh*, Faiz Najmuddin Ghazi and Afiq Muizz Rasidi \\ Department of General Surgery, Kuala Krai Hospital, Kelantan, Malaysia
}

\begin{abstract}
Objective: The aim of this study was to determine if the liver biomarkers such as Alanine Transaminase (ALT) and Aspartate Transaminase (AST) can be used as diagnostic markers in blunt Liver Injury (LI).

Methods: A retrospective review of all patients with blunt abdominal trauma from November 2013 until November 2014 was made. Patients with abnormally raised liver enzymes were identified and analyzed. Besides demographic data, other parameters investigated were Injury Severity Score (ISS), associated abdominal signs, grading of LI and its clinical management. A matched control was selected concurrently.

Results: A total of 34 patients were enrolled. Their mean ISS was 12 (range $4-41$ ). Ten had mild to moderate LI, grade 2 and 3 (70\% and 30\% respectively). The mean age were $43.1 \pm 15.7$ years with most (90\%) being males. Most of the patients (80\%) were hemodynamically stable at presentation. Four patients (40\%) demonstrated no abdominal signs suggestive of LI. The mean AST and ALT level were $406.8 \pm 307.0 \mathrm{U} / \mathrm{L}$ and $377.7 \pm 308.9 \mathrm{U} / \mathrm{L}$ respectively. CT scan was conducted in $60 \%$ of the patients. Raised liver enzymes consistently demonstrated high sensitivity of predicting LI (80 - $90 \%$ ). A double elevation of AST and ALT are associated with $90 \%$ sensitivity, but has low specificity ( $62 \%$ and $66 \%$ respectively). Nevertheless elevation of ALT by three times was strongly related with LI (OR 34.2; 95\% CI, $3.4-337.3$ ) and improved specificity to $80 \%$
\end{abstract}

Conclusion: The use of liver enzymes in blunt hepatic trauma is very helpful with elevation of ALT by three times has high sensitivity (90\%) and specificity (80\%).

\section{Introduction}

Liver is the second most common organ prone to injury following blunt abdominal trauma [1]. Blunt liver injury (LI) can vary from minor contusion to avulsion and has been associated with morbidity and mortality [2]. Patients with unstable hemodynamics with hemoperitoneum do not pose a diagnostic challenge since the plan of care is clear [3]. However, difficulties still exists for further investigation in those with minimal clinical findings and stable clinically [1-3].

Focused Assessment of Sonography in Trauma (FAST) is a bedside ultrasound examination to identify presence of free intraperitoneal or pericardial fluids. It has limitations in blunt abdominal trauma with an overall sensitivity for detection of LI reported to be as low as $64 \%[3,4]$. Its sensitivity is even lower when parenchymal injuries associated with no free fluid [5]. In contrast, CT scan has a well-established sensitivity (92-97\%) and specificity (98.7\%) in diagnosing LI and is therefore currently regarded as an imaging method of choice in stable blunt abdominal trauma [6]. Unfortunately not many medical institutions have a ready access to it.

Recently, raised liver enzymes such as Aspartate Transaminase (AST) and Alanine Transferase (ALT) have been shown to have both excellent diagnostic and prognostic values in blunt LI. In this study we aim to investigate if measurement of liver enzymes can be used in a local setting. If they can be applied locally, it will be a cheaper and easier but reliable method that can be used in institutions where CT scan is not readily available.

\section{Material and methods}

This is a retrospective 12-month study (November 2013-2014), which included all blunt abdominal trauma cases for patients ageing more than 12 years old who presented to the level II trauma centre in Hospital Kuala Krai, Kelantan, Malaysia. Our hospital is the only specialist hospital located in the southern part which provides health care services to approximately 320000 people. The Emergency Department (ED) receives approximately 44,000 visits annually with $13 \%$ reported to be trauma related cases. The hospital covered an area of $11000 \mathrm{~km}^{2}$ with two non-specialist district hospitals.

Patients with abnormally raised liver enzymes (AST and ALT) were identified and enrolled. Apart from demographic data, other parameters interested were Injury Severity Score (ISS), associated abdominal signs, grading of liver injury and its clinical management were also recorded. Exclusion criteria were known chronic liver disease, delayed presentation (more than 24 hours), blood samples taken 12 hours following trauma and penetrating liver injury. Positive abdominal sign is defined as when two out of the three signs such as 1) external wound at right hypochondriac (RHC) or right lower chest, 2) RHC pain and 3) Tenderness at RHC during palpation. LI was graded based on the American Association for Surgery of Trauma (AAST), as assessed mostly by CT scan.

Correspondence to: Asri Che Jusoh, General Surgeon, Department of General Surgery, Kuala Krai Hospital, Kelantan, Malaysia, Tel: +609 9663000; Ext 1584; E-mail: asricj@yahoo.com

Key words: liver injury, abdominal trauma, AST, ALT

Received: December 14, 2015; Accepted: January 22, 2016; Published: January 26,2016 
A matched control is selected concurrently as defined by having blunt abdominal trauma with no proven LI as confirmed by ultrasound or CT scan. An estimated sample size calculated for $90 \%$ power, a of $0.05,1: 2$ for case:control to detect a minimum odds ratio (OR) of 30 yielded a total of 27 patients ( 9 cases and 18 controls). Statistical analysis was performed with SPSS version 18 using a Chi-squared test for discrete variables while unpaired t-test was used for continuous variables. The Level of significance was set at $p<0.05$. AST and ALT levels $\geq 35 \mathrm{U} / \mathrm{L}$ and $45 \mathrm{U} / \mathrm{L}$ respectively we considered abnormal.

\section{Results}

A total of 34 patients were enrolled. Their mean ISS was 12 (range 4 - 41). Ten had mild to moderate LI, grade 2 and 3 (70\% and $30 \%$ respectively). The mean age were $43.1 \pm 15.7$ years with most $(90 \%)$ being males. Most of the patients $(80 \%)$ were hemodynamically stable at presentation. Two unstable patients were due to multiple long bone and pelvic fractures. Four patients (40\%) demonstrated no positive signs suggestive of liver injury. Cases and controls were matched according to age, gender, mechanism of injury, hemodynamics at presentation and types of imaging conducted (table 1).

Interestingly, both groups had similar rates of positive abdominal signs $(60 \%$ for cases and $54.2 \%$ for controls, $\mathrm{p}=0.7)$. Similarly, mean Total white counts (TWC) was also not statistically significant between the two groups (15.1 vs. 18.2, $\mathrm{p}=0.175)$. As expected, the mean ISS was significantly higher among cases when compared to controls (18.8 vs. 10.0, $\mathrm{p}<0.05)$.The mean AST and ALT levels were significantly higher among cases when compared to control respectively (Table 1). Elevation of AST and ALT levels by two times is consistently associated with high sensitivity (90\%) of detecting LI. However, the specificity is low (62\% and $66 \%$ respectively). Surprisingly, elevation of AST by three times had lower sensitivity and specificity ( $80 \%$ and $71 \%$ respectively; $\mathrm{OR}=9.7)$. In contrast, elevation of ALT level by three times is the most reliable marker with $90 \%$ sensitivity and $80 \%$ specificity $(\mathrm{OR}=34.2: 95 \%$ CI, 3.4 - 337.3) (Table 2).

No liver related morbidity was observed with all cases successfully managed conservatively. There was a single mortality case which

Table 1. Investigated clinical parameters

\begin{tabular}{|l|c|c|c|}
\hline Parameters & Cases (n=10) & Control (n=24) & P value \\
\hline Age (years) mean \pm SD & & & \\
\hline Gender (M:F) & $43.1 \pm 15.7$ & $32.4 \pm 13.5$ & $0.05^{\mathrm{a}}(\mathrm{NS})$ \\
\hline Mechanism of injury (MVA-related) n (\%) & $9(90)$ & $16(66.7)$ & $0.38^{\mathrm{b}}(\mathrm{NS})$ \\
\hline Hemodynamics (stable at presentation) n (\%) & $8(80)$ & $23(95.8)$ & $0.07^{\mathrm{b}}(\mathrm{NS})$ \\
\hline Positive abdominal signsn (\%) & $6(60)$ & $13(54.2)$ & $0.70^{\mathrm{b}}(\mathrm{NS})$ \\
\hline Best imaging done (US:CT) & $(6: 4)$ & $(11: 13)$ & $0.75^{\mathrm{b}}(\mathrm{NS})$ \\
\hline Mean AST U/L & $406.8 \pm 307.0$ & $147.2 \pm 195.4$ & $0.006^{\mathrm{a}}$ \\
\hline Mean ALT U/L & $377.7 \pm 308.9$ & $133.8 \pm 217.9$ & $0.01^{\mathrm{a}}$ \\
\hline Mean TWC X $10^{3} / \mathrm{uL}$ & $15.1 \pm 4.1$ & $18.2 \pm 6.0$ & $0.18^{\mathrm{a}}(\mathrm{NS})$ \\
\hline Mean ISS & $18.8 \pm 11.0$ & $10.0 \pm 5.5$ & $0.03^{\mathrm{a}}$ \\
\hline
\end{tabular}

${ }^{\mathrm{a}}$-test

${ }^{\mathrm{b}}$ chi squared test

NS : Not significant.

ISS : Injury Severity Score

MVA: Motor vehicle accident

US: Ultrasound

CT: Computer tomography

TWC: Total white counts
Table 2. Estimated sensitivity, specificity, positive predictive value (PPV) and negative predictive value (NPV) for the liver enzymes in predicting liver injury.

\begin{tabular}{|l|c|c|c|c|}
\hline Liver enzymes & Sensitivity (\%) & Specificity (\%) & PPV (\%) & NPV (\%) \\
\hline AST $\geq 2 \mathrm{x}$ & 90 & 62 & 50 & 93 \\
\hline ALT $\geq 2 \mathrm{x}$ & 90 & 66 & 52 & 94 \\
\hline AST $\geq 3 \mathrm{x}$ & 80 & 71 & 53 & 89 \\
\hline ALT $\geq 3 \mathrm{x}$ & 90 & 80 & 64 & 95 \\
\hline
\end{tabular}

PPV $=$ Positive predictive value

$\mathrm{NPV}=$ Negative predictive value

occurred due to severe poly-trauma with multi-organ failures.

\section{Discussion}

In blunt abdominal trauma, hemodynamically stable patient with minimal signs is often managed in general ward or sometimes discharged. Unfortunately, RHC pain is a fairly unreliable indicator of LI even if performed by skilled hands $[1,2,7]$. Forty percent of the patients admitted to our hospital showed no typical signs and symptoms of LI. Although conservative management is becoming a standard of care for hemodynamically stable patient, high grade (grade $\geq$ III) LI requires intensive monitoring since nearly $30 \%$ tend to require adjunctive treatments including ERCP or percutaneous drainage of biliomas [8]. Therefore, in any cases of blunt abdominal trauma admitted especially to district hospitals, it is of paramount importance to correctly and promptly diagnose the LI which will allow patients to be properly triaged and referred urgently to specialist hospital. Other than CT scan, liver enzymes appear to have good sensitivity and specificity which surpasses that of ultrasound.

The levels of both enzyme (AST and ALT) are expected to rise following LI, as demonstrated by several studies [2-4]. Its diagnostic property is excellent despite of no consistent level concluded. In a previous study, Zhiqiang et al. [3] reported that ALT level of $>57 \mathrm{U} / 1$ is most suitable in detecting LI when compared to other liver markers with sensitivity of $92.2 \%$, specificity of $84.8 \%$, PPV of $85.6 \%$ and NPV of 91.8\% [3]. Similarly, Srivastava et al. [4] also reported that ALT is able to predict LI with higher sensitivity and specificity of $100 \%$ and $98.9 \%$ respectively ${ }^{[4]}$. Although AST was raised in all of the patients, ALT was significantly associated with it (OR 109.8), sensitivity, specificity, PPV and NPV of $94.5 \%, 86.4 \%, 89.7 \%$ and $92.7 \%$ respectively [6]. Comparable to other studies, in our series both AST and ALT levels were significantly increased with triple elevation of ALT (ALT > 135 $\mathrm{U} / \mathrm{L}$ ) appeared to be the most reliable.

Many authors had demonstrated significant correlation between the level of liver enzymes (AST and ALT) and the grade of LI. Recently, Bilgic et al. [8] reported significantly higher AST, ALT and LDH levels in grade 3, 4, and $5 \mathrm{LI}$ when compared to grade 1 and 2. Furthermore, the presence of other visceral injuries has been reported not to influence the level of liver enzymes [8]. Additionally, Stassen et al. [10] demonstrated that, probability of suffering from major injury (grade $\geq$ 3) was $44 \%$ in liver enzymes of $>360 \mathrm{IU} / \mathrm{L}$ while a level of $<360 \mathrm{IU} / \mathrm{L}$ is not associated with major LI despite a negative FAST [10]. Tan et al. [6] also concluded that more than double elevation of both enzymes correlated with major injury [6].

Many authors preferred ALT over AST due to its higher sensitivity and specificity $[4,6]$. In this study, triple elevation of AST was inferior than ALT in predicting LI. In addition, Srivastava et al. [4] noticed that the median ALT in survivors of LI was significantly lower than those who died (690 U/L and $1960 \mathrm{U} / \mathrm{L}$ respectively). They concluded that 
raised ALT successfully predicts LI with the higher degree suggesting high grade LI [4]. On the other hand, Zhiqiang et al. [3] noted that no correlation exist between the degree of elevated liver enzymes and the grade of injury [3]. However, based on our findings, we cannot make any conclusive suggestion on this matter since a complete spectrum of LI grade was not analysed. Furthermore, the study was not designed for this purpose. A lower prevalence of cases in the total number of investigated population (29\%), may explain the low (64\%) PPV for triple elevation of ALT in our findings. In contrast, the prevalence of LI cases in most series were approximately $50 \%-60 \%[1,4,6,8]$.

Combining elevated enzymes and raised total white count or FAST have been shown able to improve its sensitivity and specificity. Lee et al. [1] suggested that a combination of raised enzymes (AST $>100 \mathrm{IU} / \mathrm{L}$ and ALT $>80 \mathrm{IU} / \mathrm{L})$ and raised TWBC $(>10000)$ can be used as an early warning system for possible LI with sensitivity of $90 \%$ and specificity of $92.3 \%$ respectively [1]. Similarly, incorporating FAST with elevated enzymes will improve the sensitivity and specificity to $88 \%$ and $98 \%$ respectively especially in children [9]. Unfortunately, we have not seen any significant difference in the degree of leucocytosis in both groups.

There are some limitations to our study. It was retrospective in nature with relatively small sample size as compared to others. Therefore, the possibility of committing type 1 error (false positive) is high since approximately $50 \%$ of the control group had only ultrasound rather than CT scan. Moreover, $20 \%$ of the control had triple elevation of both enzymes. Future prospective study with larger sample size encompassing entire spectrum of LI and control group taken only from those who had CT scan is very much needed.

\section{Conclusion}

The level of liver enzymes particularly triple elevation of ALT is useful in predicting blunt hepatic trauma and provides good sensitivity (90\%) and specificity (80\%). Patients with stable hemodynamics with no obvious signs of LI but has raised liver enzymes should alert a local trauma physician about a possibility of LI in which they can be transferred to the specialist hospital for further imaging and management.

\section{Authors' contribution}

Asri che Jusoh involved in designing, compiling and writing the paper.
Faiz Najmuddin Ghazi participated in doing literature search and organizing the reviewed paper.

Afiq Muizz Rasidi involved in acquisition of data and prepares the case history.

\section{Conflict of interest}

Asri Che Jusoh, Ahmad Faiz Najmuddin Ghazi and Afiq Muiz Rasidi declare that we have no conflict of interest and no fund involved.

\section{References}

1. Lee WC, Kuo LC, Cheng YC, Chen CW, Lin YK, et al. (2010) Combination of white blood cell count with liver enzymes in the diagnosis of blunt liver laceration. $\mathrm{Am} \mathrm{J}$ Emerg Med28: 1024-1029. [Crossref]

2. Ritchie AH, Williscroft DM (2006) Elevated liver enzymes as a predictor of liver injury in stable blunt abdominal trauma patients: case report and systematic review of the literature. Can J Rural Med 11: 283-287. [Crossref]

3. ZHIQIANG TIAN, HONG LIU, XIAOFANG SU, ZHENG FANG, ZHITAO DONG et al. (2012) Role of elevated liver transaminase levels in the diagnosis of liver injury after blunt abdominal trauma. ExpTher Med 4: 255-260. [Crossref]

4. Srivastava AR, Kumar S, Agarwal GG, Ranjan P (2007) Blunt abdominal injury: serum ALT-A marker of liver injury and a guide to assessment of its severity. Injury 38: 10691074. [Crossref]

5. Richards JR, McGahan JP, Pali MJ, Bohnen PA (1999) Sonographic detection of blunt hepatic trauma: hemoperitoneum and parenchymal patterns of injury. $J$ Trauma 47: 1092-1097. [Crossref]

6. Tan KK, Bang SL, Vijayan A, Chiu MT (2009) Hepatic enzymes have a role in the diagnosis of hepatic injury after blunt abdominal trauma. Injruy 40: 978-983. [Crossref]

7. Schurink GW, Bode PJ, van Luijt PA, van Vugt AB (1997) The value of physical examination in the diagnosis of patients with blunt abdominal trauma: a retrospective study. Injury 28: 261-265. [Crossref]

8. Bilgic I, Gelecek S, Akgun AE, Ozmen MM (2014) Predictive value of liver transaminases levels in abdominal trauma. Am J Emerg Med 32: 705-708. [Crossref]

9. Sola JE, Cheung MC, Yang R, Koslow S, Lanuti E, et al. (2009) Pediatric FAST and elevated liver transaminases: An effective screening tool in blunt abdominal trauma. $J$ Surg Res 157: 103-107. [Crossref]

10. Stassen NA, Lukan JK, Carrillo EH, Spain DA, Norfleet LA, et al. (2002) Examination of the role of abdominal computed tomography in the evaluation of victims of trauma with increased aspartate aminotransferase in the era of focused abdominal sonography for trauma. Surgery 132: 642-646. [Crossref]

Copyright: (C2015 Jusoh AC. This is an open-access article distributed under the terms of the Creative Commons Attribution License, which permits unrestricted use, distribution, and reproduction in any medium, provided the original author and source are credited. 